\title{
Animal Activism and Environmentalism in an Age of Extinction
}

\section{John Kinder}
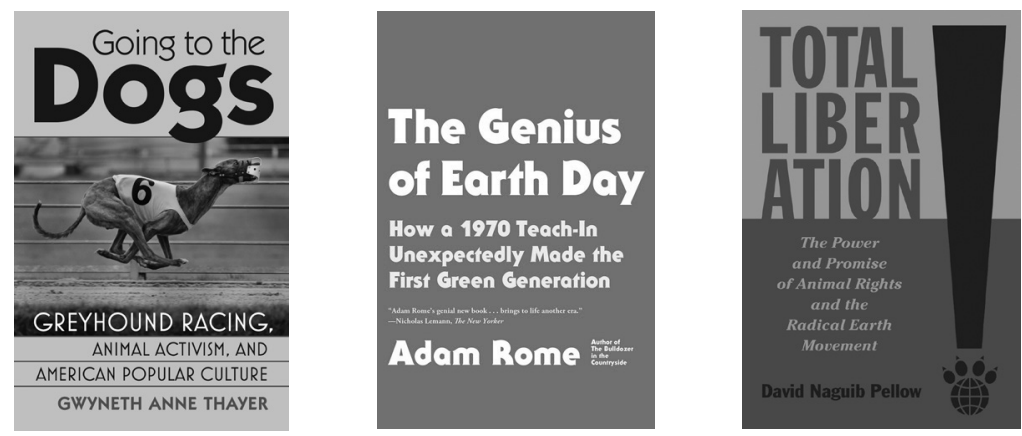

GOING TO THE DOGS: Greyhound Racing, Animal Activism, and American Popular Culture. By Gwyneth Anne Thayer. Lawrence: University Press of Kansas. 2013.

THE GENIUS OF EARTH DAY: How a 1970 Teach-in Unexpectedly Made the First Green Generation. By Adam Rome. New York, NY: Hill and Wang. 2013. TOTAL LIBERATION: The Power and Promise of Animal Rights and the Radical Earth Movement. By David Naguib Pellow. Minneapolis: University of Minnesota Press. 2014.

On June 19, 2015, a team of biologists, including Paul R. Ehrlich, author of the 1960s bestseller The Population Bomb (1968), published a brief study in 
Science Advances on the future of life on the planet. Their forecast was dire: the world is in the midst of a sixth mass extinction, a cataclysmic biotic collapse on par with the end of the dinosaurs 65 million years ago. Since 1900, more than 450 vertebrate species have disappeared, an extinction toll that will continue to increase over the next few centuries. "If the currently elevated extinction pace is allowed to continue," they warn darkly, "humans will soon (in as little as three human lifetimes) be deprived of many biodiversity benefits" (read: the basic ecological conditions necessary to sustain life as we know it). And it is not like we can simply wait for things to improve: "On human time scales, this loss would be effectively permanent because in the aftermath of past mass extinctions, the living world took hundreds of thousands of years to rediversify." As if that were not enough, the report's authors blame human activity for the looming crisis. In their reckoning, global society has exploited the Earth's living systems to the breaking point - and everyone, every thing, will pay the price.

Ehrlich and company are the latest in a long line of commentators to raise the specter of anthropogenic (human-induced) extinction. As journalist Sarah Kaplan points out, a 1998 poll of four-hundred scientists taken by the American Museum of Natural History found that " 70 percent believe the Earth is in the midst of one of its fastest mass extinctions, one that threatens the existence of humans as well as the millions of species we rely on."2 Since that time, warnings of global catastrophe have only gotten louder. In her Pulitzer Prize-winning The Sixth Extinction: An Unnatural History (2014), writer Elizabeth Kolbert predicts the current extinction event will "continue to determine the course of life long after everything people have written and painted and built has been ground into dust and giant rats have - or have not - inherited the earth." ${ }^{3}$ Recently, world leaders have also begun to raise alarms about the implications of environmental destruction. At the 2015 graduation of the U.S. Coast Guard Academy, Barack Obama called climate change a "serious threat to global security." And just one day before the release of the Science Advances report, to the outrage of climate-change deniers and Earth exploiters worldwide, Pope Francis issued a more than one-hundred page encyclical condemning human destruction of the world's ecosystems. ${ }^{5}$ Meanwhile, twenty-first century popular culture churns out apocalyptic visions of mass extinction and environmental collapse. Looking toward the future, films like John Hillcoat's The Road (2009), David Michôd's The Rover (2014), and Frank Miller's Mad Max: Fury Road (2015) paint a grim picture of a biosphere on the brink of destruction.

And yet, when confronted with the most important topic of our time- - possibly of all time - the field of American Studies has largely responded with silence. ${ }^{6}$ In a recent article in American Quarterly, Matthew Schneider-Mayerson observes, "American studies, the academic discipline arguably most dedicated to progressive political engagement, social justice, and activism, has for the most part ignored climate change and the still-accelerating consumption of fossil fuels despite our awareness of the catastrophic environmental and human consequences." Much the same can be said about American Studies' engage- 
ment with human-animal studies (HAS), an interdisciplinary field dedicated to understanding the complex relationships between human and nonhuman animals. Over the last two decades, HAS scholars in philosophy, literary studies, anthropology, history, gender studies, and elsewhere have produced groundbreaking studies on a range of animal-related topics - from the gendered politics of deer hunting to the social construction of (the processed dead animal flesh marketed to Americans as) "meat." Yet HAS students would be hard-pressed to identify an "animal turn" in most American Studies departments or at the fields' top conferences. American Studies remains a decidedly human-centered discipline, with the vast bulk of the Earth's living inhabitants assigned a secondary — and often invisible- - status. ${ }^{9}$

Fortunately, three new works chart directions that future American Studies scholars might follow. At first glance, they share little in common, beyond their broad interest in animal or environmental matters. Historian Gwyneth Anne Thayer's Going to the Dogs: Greyhound Racing, Animal Activism, and American Popular Culture (2013) traces the rise and fall of greyhound racing in American culture. Historian Adam Rome's The Genius of Earth Day: How a 1970 Teach-In Unexpectedly Made the First Green Generation (2013) examines a key turning point in the history of twentieth century environmental activism. Sociologist Naguib Pellow's Total Liberation: The Power and Promise of Animal Rights and the Radical Earth Movement (2014) takes the reader on an ethnographic tour of radical animal rights and environmental groups. In terms of structure and technique, they could not be more different. Going to the Dogs is, in many ways, a work of sports history in the vein of Eliot Gorn's The Manly Art (1986) or Steven A. Riess's City Games (1991). ${ }^{10}$ It is as much interested in the evolution of the greyhound racing industry - and the social context in which it developed - as in the dogs themselves. The Genius of Earth Day takes a "dayin-the-life" approach, using dramatic detail and narrative to recreate the sights, sounds, and excitement of early 1970s America. Total Liberation, by contrast, is a highly theorized meditation on the possibilities of radical politics and the multi-faceted nature of state repression. Collectively, all three books contribute to what might be described as a new activist history, one that looks beyond more familiar political movements (e.g., African American civil rights, feminism, antiwar). They also illustrate the range of possibilities open to American Studies scholars eager to integrate nonhuman animals and the environment into their research and teaching.

In Going to the Dogs, Gwyneth Anne Thayer uses the history of greyhound racing to explore conflicts over entertainment, social identity, and the status of animals in modern America. The sport's origins can be traced to the rural tradition of coursing, which was introduced to the United States by English immigrants in the late nineteenth century. During a coursing event, a pair of greyhounds is made to chase a live lure (usually a jackrabbit) in an open field. Dogs do not win by killing the quarry; rather, the "chief aim of the competition" is to judge the animals" speed and agility (5). Around World War I, Owen Patrick Smith revolutionized 
greyhound racing when he replaced the live bait with a mechanical lure. The Blue Star Amusement Park, the first track to feature Smith's invention, opened in Emeryville, California in 1919. However, the early tracks - and greyhound racing in general - were plagued with problems from the start. According to critics, greyhound races were havens of gambling, drunkenness, and crime. Many tracks folded within months, sometimes days (Blue Star barely lasted two years), and "dogmen" - the name given to the greyhounds' owners and handlers-led a peripatetic lifestyle, roaming from state to state in an endless search of competition. In the 1920s and 1930s, greyhound tracks popped up throughout the South and Midwest. Yet the sport failed to achieve a national foothold. Anti-greyhound forces - led by members of the horse racing industry - succeeded in banning greyhound racing across much of the United States.

One bright spot on the dog-racing map was Florida. After World War II, "promoters sought to link Florida greyhound racing with plentiful leisure, high fashion, high living, and an emerging celebrity culture" (100). Ads for races featured photographs of movie stars and bikini-clad Miss America contestants. According to Thayer, "The message was clear: greyhound racing in Florida signified sexy, glamorous, sporting fun" (119). Still, outside of Florida and a handful of other states, the sport's heyday was short-lived. By the 1970s and 1980s, a "more competitive and diversified entertainment market rendered it increasingly difficult for greyhound promoters to attract fans" (10). Savaged in the press for their "utilitarian use of animals," racing advocates tried to rescue the sport's reputation, but it was too little, too late (130). Today, even industry insiders concede that greyhound racing's days are numbered.

A history of greyhound racing in America would be valuable enough. However, Thayer offers much more than that, interweaving her study - in the best American Studies tradition - with nuanced discussions of gender, economics, and politics. She is especially attentive to debates about class, a theme that pervades the entire book. While "promoters increasingly sought to characterize greyhound racing as the elite "Sport of Queens," it struggled to escape its lowbrow, if not criminal, reputation (49). From the sport's early days, critics deployed classbased attacks against racing events, their patrons - even the dogs themselves. In Kentucky, the site of a fierce (and ultimately failed) campaign to legalize the sport in the 1930s, racing was viewed as a "working- and middle-class spectator sport inextricably linked with gambling" and vice (71). At the Kentucky Supreme Court, state attorneys successfully argued that dogs and horses "belonged to two fundamentally different categories of animals and only exhibited an 'artificial similarity" (77). According to Thayer, the "case established a precedent by which each state would have to legalize dog racing separately" (77). The court's decision also illustrates a core principle of human-animal studies: that ideas about animals are not predetermined by biology or "nature." On the contrary, social forces like class and regional interest play outsize roles in shaping the moral and legal status assigned to different animal species. 
Just as important, Thayer's book reminds us that attitudes toward animals change according to shifting cultural values. Early in the twentieth century, many Americans "viewed the role of dogs both as predetermined and as limited to duties beneficial to humans" (2). Dogmen in particular regarded their greyhounds as "property" to be exploited for economic gain, a mindset that persists among racing insiders to this day (130). Over the course of the century, however, more and more Americans began to embrace what Thayer describes as a "modified perspective toward all dogs, one that characterized animals as deserving lives free from toil" (2). By the 1970s and 1980s, greyhound racing was increasingly vulnerable to attacks by animal protectionists and journalists, who published damning exposés on "the mass destruction of dogs once they were viewed no longer viable for racing" (13). The details make for tough reading. Tens of thousands of animals too weak or slow for a career on the track were shot, killed by lethal injection, dumped in open graves, or dropped off at animal shelters, where the dirty work of bulk killing was left to the very groups charged with saving their lives. Thousands more were shipped off for medical research and experimentation at state universities across the Midwest. To blunt public criticism, the racing industry eventually began to promote the adoption of ex-racing greyhounds. (Thayer acknowledges that her interest in the topic came after adopting an ex-racing dog in 2004.) However, the drive effectively backfired as "a growing number of Americans became convinced that greyhound racing should be eliminated altogether" (190).

Going to the Dogs suggests that - in the right circumstances - animal activism can be a powerful weapon for cultural change. Yet readers looking for a simple narrative of "good" (kind-hearted animal protectionists) triumphing over "evil" (greyhound-killing dogmen) will be disappointed. For starters, Thayer makes clear that animal advocacy was not the sole cause of the sport's demise. Plenty of factors played a part, including the passage of the Indian Gaming Regulatory Act of 1988, which tilted the betting table toward untaxed Native American casinos (186). Moreover, Thayer conveys considerable sympathy toward dogmen and dog racing in general, even as she details its many horrors. She points out that greyhounds are "naturally lean and muscular, leading those who are unfamiliar with the breed," including animal protectionists, "to sometimes conclude-erroneously - that they are malnourished or starved" (17). Indeed, her research seems to support greyhound racers' view that they are "unfairly singled out for their use of animals" (146). To cite just one example: dog racing has attracted far more criticism than horse racing, despite the fact that thoroughbred horses are "considerably more fragile" than their greyhound counterparts (144). Lacking the economic or social resources to fight back, Thayer notes, many "dogmen have felt increasingly powerless to confront the changing landscape before them" (183). I cannot say I pity them or that I mourn the sport that was their livelihood. To me, greyhound racing is a vile activity, only a smidge above bear baiting and bull fighting in its disregard for animal suffering. Nevertheless, I believe even 
greyhound racing's staunchest critics will find much to learn - and much to value - in Thayer's deeply researched and carefully written book.

Adam Rome's The Genius of Earth Day uses one of environmentalism's great success stories to examine the power (and pitfalls) of eco-activism on a mass scale. The story of Earth Day began, modestly enough, in September 1969, when Wisconsin Senator Gaylord Nelson called for a "nationwide teach-in on the environment" the following spring (57). Inspired by the antiwar movement, Nelson hoped that the teach-in model might prove a useful means of raising critical awareness of environmental issues. As it turned out, Earth Day quickly morphed into a cultural phenomenon its planners could have never imagined. On April 22, 1970, Earth Day celebrations were held in communities, large and small, across the United States. By the time it was over, more people had taken part in Earth Day events than in the "biggest civil-rights and antiwar demonstrations in the 1960s" (10). One of Rome's central arguments is that Earth Day was more than a "symbolic" demonstration of eco-friendly protest. It was, in the author's words, a "transformative event," fundamentally altering a generation's relationship to environmental issues (xi).

I will admit: when I started the book, I was a bit skeptical. I regularly teach a class on the United States in the 1970s, and-despite my long-term interest in environmental history-I typically make only passing reference to Earth Day. The Genius of Earth Day has changed all that. Rome makes a persuasive case that Earth Day was not only the most important expression of environmental activism of the past few decades, but also one of the most significant political protests - on any issue - in modern U.S. history. Earth Day's success, Rome contends, can be attributed to several factors. One was the ideological breadth of its organizers and participants. By "conservative estimate," 35,000 speakers took part in Earth Day events (165). Some, like Republican Representative John Saylor of Pennsylvania, championed a reformist approach to protecting the environment. The best way of effecting change, he told students at Penn State University, was to "collaborate with those who have power" (137). Other speakers offered more radical critiques, linking current environmental problems to the "exploitative character of capitalism" and the "wastefulness of a newly affluent society" (168). As Rome makes clear, the events' leaders tended to be white, educated, and middle-class - characteristics shared by the activists profiled in both Going to the Dogs and Total Liberation. That said, Earth Day could not be boiled down to a single message or ideological slogan.

Even more critical to Earth Day's success was Nelson's “willingness to let others take ownership of the teach-in," a decision Rome suggests "encouraged an entrepreneurial approach to problem-solving" (274). Local people organized the vast majority of Earth Day events, tailoring their activities to address homegrown issues and circumstances. In New York City, where automobile pollution was a constant concern, 250,000 people crowded onto Fifth Avenue, which had been transformed into a pedestrian park. In Birmingham, Alabama, a city notorious for its poor air quality (the second worst in the nation behind Gary, Indiana), students 
and young professionals organized an entire week of environmental events. The highpoint of "Right to Live Week" came on Earth Day itself, when a local doctor, Marshall Brewer, told a crowd of hundreds: "We have two choices. We can spend, pollute and be as merry as we can or we can listen to what the experts and young people all over the country are saying today" (133). Throughout the United States, K-12 schoolchildren picked up trash, watched environmental films, and listened to local speakers. Even the television networks got in on the act. The National Educational Television, a precursor to the Public Broadcasting Service, "devoted all of its airtime on April 22 to Earth Day programming," while NBC's Today show dedicated an entire week to environmental themes (160). As a result of this varied activity, "Earth Day was almost unfathomably big — not one event but 12,000 or 13,000," each one unique (116).

Rome's book will be a popular among both students and teachers. Although The Genius of Earth Day approaches 350 pages in length, it's never unwieldy. Each chapter is meticulously organized around a specific aspect of Earth Day (its pre-history, events, leaders, etc.), and Rome's past experience as a working journalist serves him well. His prose is crisp, detailed, and peppered throughout with narrative flair. However, the book's greatest contribution is not Rome's dramatic, at times rousing, re-telling of the day's events, but his discussion of Earth Day's legacies. Summarizing the event's significance, Rome contends, "The post-Earth Day eco-infrastructure gave the environmental movement staying power. After the passions of Earth Day cooled, the first generation of environmental lobbyists ensured that politicians still felt pressure to protect the environment" (210). Across the United States, newspapers dedicated regular columns to the "e beat," cities built ecology centers, and schools incorporated environmental issues into students' curricula. According to Rome, after Earth Day, “Americans no longer took for granted that technological development was unquestionably good" (218).

It is tempting to read The Genius of Earth Day less as a work of cultural history and more as a blueprint for future activism. (The blurbs on the back of my paperback copy seem to encourage just such an interpretation.) However, the book's epilogue suggests that replicating Earth Day's achievements will not be easy. In 1990, a new group of organizers held a twentieth anniversary Earth Day celebration. Although the latter event was better funded and generated a larger audience than the 1970 original, Earth Day 1990 was far less impactful. The reasons why are telling. To begin with, the environmental crisis lacked the novelty it had in 1970. Organizers "sought to 'enlist' people in a well-defined movement, not to empower them to work out their own vision of how they might make a difference" (279). Moreover, the event's leaders favored a "top-down" approach, effectively eliminating the spontaneity and diverse character that made the 1970 event relevant to so many people (278). Today's environmental professionals might be better at "leading campaigns" and "making arguments," but Rome laments "they seldom inspire the deep reflection that might make the environmental movement dramatically bigger and stronger" (280). 
So if Earth Day 3.0 won't save the planet, what will? Naguib Pellow's Total Liberation offers some provocative suggestions. Pellow's goal, as he states in the book's preface, is to understand how "activists seek to effect change, particularly in the face of state and corporate repression" (xiii). To find out, he conducted hundreds of hours of interviews, attended animal liberation and environmental conferences and meetings, and analyzed activist-produced websites, newsletters, and zines. Although Pellow's book occasionally touches on "mainstream" or "progressive" organizations (of the sort that are highlighted in Going to the Dogs and The Genius of Earth Day), the bulk of the book focuses on radicals, activists who-by Pellow's definition- "seek to replace the existing political and economic system with something entirely different" (57). Groups like EarthFirst!, the Earth Liberation Front (ELF), and the Animal Liberation Front (ALF) "contend that confrontation and illegal direct action are far more effective than reformist, insider tactics" (33). Yet Pellow's book is as much about ideas as about actions. Pellow is especially interested in radical activists' promotion of "total liberation," an emancipatory political "framework that sees the exploitation of ecosystems and nonhuman animals as necessarily linked to the inequalities within human society, and that recognizes that there can be no liberation of one without the other" (19). At its core, Total Liberation examines activists' efforts to grapple with both the demands of total liberation and the "racism, patriarchy, heteronormativity, nativism, class, and imperialism that have traditionally permeated and haunted environmental and animal rights causes" (12).

A word of warning: Total Liberation is not an easy read. Pellow's writing is chock full of abbreviations, numbered lists, dense sociological theory, and lengthy definitions. The book's introduction - in which Pellow outlines, by my count, more than twenty important concepts and contexts (many of which with similar-sounding names) - is especially daunting. Yet Total Liberation is well worth the effort.

More than half of the book examines what Pellow identifies as the "four pillars" of total liberation (5). The first pillar is "an ethic of justice and antioppression for people, nonhuman animals, and ecosystems" (61). In the past, animal liberation and environmental activists have adhered to what Pellow deems "(nonhuman) nature first" narratives, frameworks that privilege saving the wilderness from exploitation above all else (62). Within (nonhuman) nature first narratives, "[c] oncerns for social justice - that is, justice for humans - are an impediment. ... particularly because the poor and people of color are (implicitly and sometimes explicitly) viewed as part of the problem" (62). Total liberationists challenge such beliefs by "integrating a serious social justice critique into their politics" (71). Equally important, they attempt to work in solidarity with Indigenous peoples and communities of color on the "front lines of environmental racism" (18). Their efforts at solidarity haven't always gone smoothly, as Pellow makes clear throughout the book. At times, radical environmental and animal groups - dominated, as they often are, by white, middle-class men-reinforce the very hierarchies they are seeking to dismantle, and the "(nonhuman) animals 
first" approach continues to dominate mainstream eco-activist discourse (92). Still, recognizing the intersectional relationship between human and nonhuman oppression represents an important theoretical leap on the part of environmental activists (one, I would wager, that the vast majority of American Studies practitioners are unable or unwilling to make).

The final three pillars of total liberation include anarchism, anticapitalism, and direct action. Pellow devotes an entire chapter (co-written with his research assistant, Hollie Nyseth Brehm) to direct action, and it is the most riveting of the entire book. More than a means to an end, direct action is a "core part of earth and animal liberation movements' tactical and philosophical repertoire, a defining feature of their cultures of resistance" (127). Practices range from roadblocks and property damage to "crop sabs," the destruction of genetically modified crops (148). The most romanticized (among the groups themselves) and publicized (among the corporate media) forms of direct action fall under the category of "monkey wrenching," a term that originated in Edward Abbey's novel The Monkey Wrench Gang (1975). Monkey wrenching, in Abbey's words, includes "ecotage, ecodefense, billboard bandits, desurveying, road reclamation, tree spiking, even fire. . . . It is one of the last steps in defense of the wild, a deliberate action taken by an Earth defender when almost all other measures have failed" (quoted in 131-32). One of the most remarkable - and truly revolutionary-aspects of environmental activists' understanding of direct action concerns the power of nonhuman animals to effect change. In the humanities, many scholars are reticent to acknowledge the concept of animal agency. ${ }^{11}$ However, Pellow and Brehm argue that "activists do not always see themselves solely as protectors of ecosystems and animals;" rather, they are "collaborators in a project of joint or total liberation" (159). In the eyes of radical activists, direct action represents a necessary - and legitimate - response to the destruction of the environment, the extinction of nonhuman animals, and the oppression of people everywhere. Not surprisingly, state and corporate actors have sought to use groups' embrace of direct action to discredit all but the most benign environmental movements.

Pellow devotes the remainder of the book to discussing activists' response to what's come to be known as the "Green Scare." Dating from the mid-2000s, the Green Scare encompasses a variety of measures aimed at criminalizing environmental and animal liberation movements. Its early phase culminated in the 2006 passage of the American Enterprise Terrorism Act (AETA), which declared as "terrorism" any effort to "harm the profits of an industry whose products are primarily based on the use of animals" (169). Under AETA and other corporatebacked legislation, earth and animal activists have been intimidated, fired from their jobs, arrested for their beliefs, and jailed in state and federal prison. Like Michel Foucault, Pellow understands state repression as a "productive set of practices" that privileges "dominant groups, social relations, and ideas" while instilling "fear" and obedience in others (164). Militant activists have resisted the Green Scare by challenging the language of the state (especially the discourse of "terrorism" that government and corporate leaders have used to neutralize 
radical earth and animal liberation movements). Activists have mobilized their resources to provide "legal, financial material, and emotional support" for their imprisoned comrades (211). They have also attempted to forge solidarity with other activist traditions whose experiences resisting state violence and surveillance date back for decades.

Total Liberation is dangerous scholarship of the best sort-the kind that makes both school officials and other academics nervous. One of Pellow's advisees, Scott Demuth, was jailed in 2009 after refusing to disclose information about the Animal Liberation Front to a grand jury. After the FBI contacted Pellow about DeMuth's case, he and his research team took to using non-university email out of concern that his communications might be monitored. On his attorney's advice, Pellow also moved his research archives to an "off-site location" out of genuine concern that "authorities could raid [his] university or home office at any time and remove materials for scrutiny and return them at their leisure (if at all)" (xviii). Why the caution? As Pellow reminds us, "The United States has a long and troubling history of silencing and disciplining academics whose research and teaching emphasize the importance of collective efforts to effect radical social change" (xx). Pellow, a tenured full professor at the University of Minnesota, has more resources as his disposal than the vast majority of academics. Even so, one cannot help but wonder how many similar projects have died on the vine because of scared administrators, anxious institutional review boards, or fearful scholars worried they might be accused of palling around with "terrorists."

For American Studies scholars, Total Liberation is dangerous in anotherand ultimately more profound - way. The "total liberation" framework articulated by animal and earth activists and (analyzed with such exhaustive rigor by Pellow and his research team) challenges us to take animals seriously, as seriously as we might take such American Studies mainstays as race, class, and gender. Total liberation suggests "one cannot fully grasp the foundations of racism, classism, ableism, heterosexism, and patriarchy without also understanding speciesism and dominionism" (20). More than a call for another "Other," total liberation "links oppression and privileges across species, ecosystems, and human populations, suggesting a theory and path toward justice and freedom - something missing from traditional models of intersectionality" (20). Is American Studies ready to take such a step? Will American Studies scholars commit the time and resources to make nonhuman oppression a priority? Do we have the intellectual elasticity to recognize intersections between the nonhuman world and ourselves? I doubt it. Then again, we might not have a choice.

When American Studies was born, people in the United States could still fantasize about wide open vistas and wild landscapes; decades before the A-bomb and the hyper-consumption of the post-World War II era, Americans could still take solace in the dream that the North American continent was simply too big, its animal populations too expansive, its natural forces too mighty in their Olympian sweep, to be fundamentally altered by the workings of humans. Today, of course, we know differently. Plagued by climate change, drought, and city-swelling 
storms, we exist in an America beset by staggering environmental destruction. Read together, Going to the Dogs, The Genius of Earth Day, and Total Liberation remind us that change is possible. Over the course of a century, greyhounds evolved from property to beloved companions. After less than a year of planning, millions of Americans rallied behind the idea of environmental protection and a "green generation" was born. Despite their relative obscurity (and despite the state's best efforts to delegitimize their work), radical earth and animal activists have articulated a vision of cross-species liberation that, in Pellow's view, offers "points of intervention, transformative change, solidarity, and coalition building across group categories" (17).

And yet, given the entrenched denial of climate change on the political Right and the ongoing exploitation of human and nonhuman animals by a capitalist system bent on profit at all costs, one cannot help but wonder: Is radical change still an option? Or have we decided, Titanic-like, to go down with the ship?

\section{Notes}

1. Gerado Ceballos, Paul R. Ehrlich, Anthony D. Barnosky, Andrés García, Robert M. Pringle, and Todd M. Palmer, "Accelerated modern human-induced species losses: Entering the sixth mass extinction," Science Advances 1:5 (June 19, 2015). DOI: 10.1126/sciadv.1400253.

2. Sarah Kaplan, "Earth is on brink of sixth mass extinction, scientists say, and it's humans' fault," Washington Post, June 22, 2015, http://www.washingtonpost.com/news/morning-mix/ $\mathrm{wp} / 2015 / 06 / 22 /$ the-earth-is-on-the-brink-of-a-sixth-mass-extinction-scientists-say-and-its-humansfault/. 269.

3. Elizabeth Kolbert, The Sixth Extinction: An Unnatural History (New York: Picador, 2014),

4. Suzanne Goldenberg, "Barack Obama sets sizzling climate action pace in push to leave legacy," The Guardian, June 26, 2015, http://www.theguardian.com/environment/2015/jun/25/ barack-obama-climate-change-legacy.

5. Emma Green, “The Pope's Moral Case for Taking On Climate Change," Atlantic, June 18, 2015, http://www.theatlantic.com/international/archive/2015/06/pope-francis-encyclical-moralclimate-change/396200/.

6. Recently, a growing number of American Studies scholars have started to buck this trend. However, writers and scholars from other fields dominate both public and academic discourse around climate change, animal extinction, and other environmental topics.

7. Matthew Schneider-Mayerson, "Necrocracy in America: American Studies Begins to Address Fossil Fuels and Climate Change," American Quarterly 67:2 (June 2015): 530.

8. Useful introductions to the field of human-animal studies include Margo DeMello, Animals and Society: An Introduction to Human-Animal Studies (New York: Columbia University Press, 2012), and Paul Waldau, Animal Studies: An Introduction (New York: Oxford University Press, 2013).

9. Notable exceptions include Janet M. Davis, The Circus Age: Culture and Society under the American Big Top (Chapel Hill: University of North Carolina Press, 2002); Katherine C. Grier, Pets in America: A History (Chapel Hill: University of North Carolina Press, 2006); Brett Mizelle, Pig (London: Reaktion, 2011); Animacies: Biopolitics, Racial Mattering, and Queer Affect (Durham: Duke University Press, 2012); John Kinder, "Zoo Animals and Modern War: Captive Casualties, Patriotic Citizens, and Good Soldiers," in Animals and War: Studies of Europe and North America, ed. Ryan Hediger (Leiden: Brill, 2012), 45-75; and selected essays in Susan Weber, Keneth L. Ames, and Matthew Wittman, eds., The American Circus (New Haven: Yale University Press, 2012).

10. Eliot J. Gorn, The Manly Art: Bare-Knuckle Boxing in America (Ithaca: Cornell University Press, 1986); Steven A. Riess, City Games: The Evolution of American Urban Society and the Rise of Sports (Urbana: University of Illinois Press, 1991).

11. On animal agency and their capacity for resistance, see Sarah E. McFarland and Ryan Hediger, Animals and Agency: An Interdisciplinary Exploration (Leiden: Brill, 2009); Jason Hribal, Fear of the Animal Planet: The Hidden History of Animal Resistance (Petrolia, CA: Counterpunch, 2010); Susan Nance, Entertaining Elephants: Animal Agency and the Business of the American Circus (Baltimore: The Johns Hopkins University Press, 2013). 